\title{
Noninvasive techniques for probing neurocircuitry and treating illness: vagus nerve stimulation (VNS), transcranial magnetic stimulation (TMS) and transcranial direct current stimulation (tDCS)
}

\author{
Mark S George ${ }^{\star, 1,2,3,4}$ and Gary Aston-Jones ${ }^{5}$ \\ ${ }^{1}$ Departments of Psychiatry, Radiology and Neuroscience, Institute of Psychiatry, MUSC Center for Advanced Imaging \\ Research, Medical University of South Carolina, Charleston, SC, USA; ${ }^{2}$ SC Brain Imaging Center of Economic Excellence, \\ Medical University of South Carolina, Charleston, SC, USA; ${ }^{3}$ Brain Stimulation Laboratory, Medical University of South \\ Carolina, Charleston, SC, USA; ${ }^{4}$ Ralph H. Johnson VA Medical Center, Charleston, SC, USA; ${ }^{5}$ Murray Chair of Excellence in \\ Neuroscience, Medical University of South Carolina, Charleston, SC, USA
}

\begin{abstract}
Although the preceding chapters discuss much of the new knowledge of neurocircuitry of neuropsychiatric diseases, and an invasive approach to treatment, this chapter describes and reviews the noninvasive methods of testing circuit-based theories and treating neuropsychiatric diseases that do not involve implanting electrodes into the brain or on its surface. These techniques are transcranial magnetic stimulation, vagus nerve stimulation, and transcranial direct current stimulation. Two of these approaches have FDA approval as therapies.
\end{abstract}

Neuropsychopharmacology Reviews (2010) 35, 301-316; doi: I0.I038/npp.2009.87; published online 19 August 2009

Keywords: TMS; VNS; neuromodulation

\section{INTRODUCTION}

The techniques discussed in this chapter serve as an appropriate last chapter for this volume on brain circuits. The preceding chapters have outlined the emerging theories about circuit abnormalities in neuropsychiatric disorders. The chapter on deep brain stimulation (DBS) reviews the most invasive method for stimulating and modifying the behavior within these circuits. In contrast, the technologies in this chapter are 'noninvasive'. We recognize that some would argue that electrically stimulating the brain is always invasive, and that many, maybe even all, brain stimulation techniques are not noninvasive. This is especially true of techniques that require general anesthesia and the implantation of a permanent pacemaker such as vagus nerve stimulation (VNS). However, for the pedagogical and nosological purposes of separating this chapter from the preceding, the word 'noninvasive' means a brain stimulation method that does not involve craniotomy and implantation of an electrode into the brain (eg DBS or

${ }^{*}$ Correspondence: Dr M George, Director, Brain Stimulation Laboratory, Medical University of South Carolina, Institute of Psychiatry, 67 President Street, Rm 502 North, Charleston, SC 29425, USA, Tel: +1 843876 5142; Fax: +1 843792 5702; E-mail: georgem@musc.edu

Received 13 April 2009; revised 12 June 2009; accepted 17 June 2009 resting on the dura (epidural cortical stimulation)). Thus, the current 'noninvasive' techniques with either existing or promising clinical applications are, in declining order of invasiveness, VNS, transcranial magnetic stimulation (TMS), and transcranial direct current stimulation (tDCS). For each of these technologies, we briefly describe the technique, discuss the major ideas concerning mechanisms of action, and then touch on safety. Following this we overview the research and clinical uses. There are now entire journals devoted to the field of brain stimulation (Sackeim and George, 2008), and entire books devoted to each of the individual techniques (George and Belmaker, 2006) as well as in-depth overviews (Higgins and George, 2008). The interested reader is referred to these. This chapter will focus on a quick and precise introduction to each with a focus on emerging clinical applications and research uses pertinent to the preceding chapters and theories.

One of the recurring themes within each of the techniques is the currently inadequate understanding of the translational neurobiological effects of the 'use parameters'. These are the pulse width, current direction, intensity, frequency, duty cycle, and the overall dose as well as dosing scheme. The future of the promising field of brain stimulation will undoubtedly involve better translating the knowledge 
gained about appropriate use parameters from preclinical cellular and nonhuman animal studies into clinical brain stimulation therapeutic uses.

\section{VAGUS NERVE STIMULATION}

The idea of stimulating the vagus nerve to modify central brain activity has been pursued for over 100 years. However, it was not until the mid-1980s that methods became available to efficiently stimulate the vagus in man and animals.

\section{Description of Method}

Although one can stimulate the vagus in several different ways, even transcutaneously, for all intents and purposes VNS in the modern literature refers to a technique where a surgeon (for human studies) or researcher (for nonhuman animal uses) wraps a unidirectional wire around the vagus nerve in the neck (see Figure 1). This wire is then connected to a subcutaneous, battery operated, generator, which is implanted subcutaneously in the left chest wall, which intermittently sends an electrical current through the wire and thus through the nerve that then conveys a signal through neural impulses into the brainstem (George et al, 2000).

VNS implantation is usually an outpatient procedure in the United States typically preformed by neurosurgeons. The battery in the device generates an intermittent electrical stimulation that is delivered to the vagus nerve. Clinicians following the patient control the frequency and intensity of the stimulation. Adjustments to the stimulation parameters are transmitted from a computer to the VNS device by a handheld infrared wand placed over the device.

The stimulating wire wrapped around the nerve is directional, and this unidirectional feature likely helps minimize efferent side effects from stimulating vagal efferent (descending) fibers. However, it is likely that at least some patients have had the leads reversed, without noticeable harm (Koo et al, 2001).

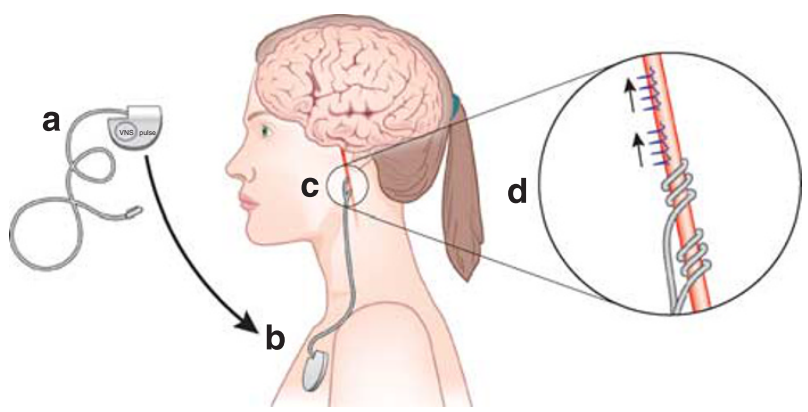

Figure 1. Clinical vagus nerve stimulation (VNS). The VNS generator (a) contains a small battery that generates electrical impulses. A surgeon implants the generator subcutaneously over the chest (b) and attaches the electrodes to the left vagus nerve (c). Intermittent signals from the VNS device travel up the vagus nerve (d) and enter the medulla. (Reprinted with permission from APPI, from Higgins and George (2008)).
The vagus nerve is actually a large nerve bundle, composed of different sized nerves (both unmyelinated and myelinated). The vagus nerve is thus a complex structure and the current form of VNS is imprecise with respect to activating discrete nerves within the bundle. Microsurgical techniques might theoretically allow for more focal VNS.

\section{Putative Mechanisms of Action}

To refresh, the vagus nerve (10th cranial nerve) enters the brain at the medulla. It is the longest cranial nerve extending into the chest and abdominal cavity. 'Vagus' comes from the Latin word for wandering, and this nerve is remarkably complex, both in where it comes from, and the variety of information it passes bidirectionally between the brain and the viscera. Traditionally, the vagus nerve has been conceptualized as modulating the parasympathetic tone of the internal organs (efferent functions). However, $80 \%$ of the signals traveling through the vagus nerve actually go from the organs back into the brain (afferent) (Foley and DuBois, 1937).

In 1938, Bailey and Bremer (Bailey and Bremer, 1938) stimulated the vagus nerve of cats and reported that this synchronized the electrical activity in the orbital cortex. In 1949, Paul MacLean and Karl Pribram carried out similar studies with anesthetized monkeys. Using electroencephalogram (EEG) recordings they found that VNS generated slow waves over the lateral frontal cortex (Maclean, 1990). The afferent fibers traveling in the vagus terminate largely in the nucleus tractus solitarius (NTS) in the medulla. The NTS, in turn, innervates the noradrenergic nucleus locus coeruleus (LC) directly (Van Bockstaele et al, 1999a, b) as well as indirectly through the rostral ventrolateral medulla (Van Bockstaele et al, 1989), which sends strong projections to LC neurons (Aston-Jones et al, 1986; Ennis and AstonJones, 1988). LC neurons project extensively throughout the neuraxis, providing prominent noradrenergic innervation in the orbitofrontal cortex and the insula, including somatotopically defined regions that may represent emotional (limbic) information (Aston-Jones, 2004). Thus, it is plausible that the NTS regulates NE release in the forebrain through its descending projections to LC afferents in the PGi. In addition, these connections show that many vagus afferent fibers connect transynaptically to areas of the limbic brain that regulate emotion. It is no surprise then that when we grieve we have the perception of having a 'broken heart', or feel like there are 'butterflies in our stomach' when we are nervous or anxious. This misplacement concerning the source of the sensory signal may reflect the fact that vagal cardiac fibers terminate in brain regions where the limbic system and gut sensations overlap.

Jake Zabara in the mid-1980s was perhaps the first to show convincingly the therapeutic benefits of VNS, although many had been considering this avenue before Zabara (Groves and Brown, 2005). Zabara discovered in a canine model of epilepsy (strychnine induced) that 
repetitive electrical stimulation of the vagus nerve was able to acutely terminate a motor seizure. Importantly, he also found that the anticonvulsant benefits could outlast the period of stimulation by a factor of four (Zabara, 1985a, b, 1992). Constant stimulation was not required for enduring anticonvulsive effects.

\section{Safety}

The adverse events associated with VNS fall into two categories - those associated with the complications of the surgery and those resulting from the side effects of stimulation. The risks associated with surgery are minimal (O'Reardon et al, 2006). Wound infections are infrequent (less than 3\%) and managed with antibiotics. Pain at the surgical site almost always resolves within 2 weeks. Rarely left vocal cord paresis persists after surgery ( $<1$ in 1000), but usually resolves slowly over the ensuing weeks.

Temporary asystole during the initial testing of the device is a rare but serious surgical complication. In approximately 1 out of 1000 cases asystole has been reported in the operating room during initial lead testing. It may be a result of aberrant electrical stimulation resulting from poor hemostatic control. That is, blood in the surgical field causes arcing of the current and the cardiac branch gets depolarized. Fortunately, no deaths have been reported as normal cardiac rhythm has always been restored. Postoperatively these patients have been able to safely use VNS. More importantly and surprisingly given the known efferent VNS effects, no cardiac events have been reported when the device is turned on for the first time after surgery.

The most common side effects associated with stimulation are hoarseness, dyspnea, and cough. They are dose dependent and correlate with stimulation intensity and can be minimized with reductions in the stimulation parameters. Interestingly, most side effects decrease with time (Sackeim et al, 2001c). Hoarseness or voice alteration is the most persistent problem. Between 30 and $60 \%$ continue to experience this side effect during times of stimulation although for reasons that are unclear this also diminishes over months to years. One would speculate that VNS might induce a parasympathetic response. However, this has been aggressively monitored and has not been an issue.

VNS therapy also affects respiration during sleep and has been shown to worsen preexisting obstructive sleep apnea/ hypopnea syndrome by increasing the number of apneas and hypopneas (Ebben et al, 2008; Holmes et al, 2003; Marzec et al, 2003; Papacostas et al, 2007). VNS should be used cautiously in patients with sleep apnea, or be supplemented with continuous positive airway pressure.

\section{Research Uses}

Owing to the cost and invasive nature of VNS, there have been no human studies in healthy adults. Recently, some have proposed transcutaneous VNS (Huston et al, 2007; Kraus et al, 2007). However, studies in patients with epilepsy or depression implanted with VNS have shown that VNS causes discrete changes in limbic structures including the cingulate gyrus, the hippocampus, and the insula (Chae et al, 2003; Henry, 2002; Henry et al, 1999). The specific network activated depends on the choice of the use parameters ( $\mathrm{Mu}$ et $\mathrm{al}, 2004$ ), suggesting that with more extensive knowledge, one could 'direct' the VNS signal within groups of patients or even individually (Lomarev et al, 2002b). Human studies using fMRI and PET techniques show that VNS induces neuronal activity changes within amygdala, hippocampus, and thalamus, all targets of the LC (Henry et al, 1998, 1999; Lomarev et al, 2002a; Mu et al, 2004). These regional changes evolve over time and vary with clinical response (Nahas et al, 2007). Additionally, VNS produces interesting improvements in cognition (Boon et al, 2006; Borghetti et al, 2007; Helmstaedter et al, 2001; Sackeim et al, 2001a; Smith et al, 2006), perhaps linked to its influence on central LC norepinephrine system. Improvements in verbal recognition memory (Clark et al, 1999) and enhanced working memory (Sackeim et al, 2001b) have also been reported. VNS also has effects on sleep and arousal states. VNS decreases daytime sleepiness in humans (Malow et al, 2001) and promotes increased attention and arousal in animals (Lockard et al, 1990). These findings suggest that VNS may be a potent modulator of cognition through influences on ascending arousal systems. CSF studies have found increases in serotonin and norepinephrine metabolites following VNS.

The animal studies to date have been more extensive, although progress in this area was slowed by the lack of small portable generators. Now that these are available for rats, VNS studies have shown the importance of the LC in the signal propagation (Krahl et al, 1998), and have also shown long-term changes in raphe firing, unlike serotonin acting medications (Biggio et al, 2009; Dorr and Debonnel, 2006; Manta et al, 2009).

Studies in rodents have examined the functional relationship between the vagus nerve and LC, in addition to the anatomical circuit connections summarized above. VNS induces expression of the immediate early gene c-fos in LC neurons (Naritoku et al, 1995). Several studies have linked the LC to the seizure-suppressant effects of vagal activity. Thus, lesions of the LC attenuate the anti-epileptic effects of VNS in the rat (Krahl et al, 1998). Anatomical targets of LC projections also show electrophysiological and neurochemical changes following VNS. Amygdala, hippocampal, and insular cortex neurons all show enhanced neuronal activity after VNS (Radna and MacLean, 1981a,b). Microdialysis studies in animals show that VNS potentiates NE release in both the amygdala (Hassert et al, 2004) and hippocampus (Miyashita and Williams, 2003). VNS also induces c-fos expression in each of these structures as well as other LC targets including the thalamus (Naritoku et al, 1995). Thus, anatomical findings show that the vagus and LC are 
connected through well-specified relay nuclei, and functional studies show that these circuits contribute to forebrain activity. These findings show that chemical or electrical stimulation of the vagus nerve alters LC activity and that of its forebrain targets suggesting that the therapeutic effects of VNS may involve the LC-noradrenergic system.

There is also intense recent work investigating the role that VNS might have on inflammation and the immune response (Ottani et al, 2009; Pavlov, 2008; Van Der Zanden et al, 2009).

\section{Clinical Studies}

The first self-contained devices were implanted in humans in 1988 in patients with intractable, medically unresponsive epilepsy. Results were positive in two large acute doubleblind controlled studies of VNS in patients with treatmentresistant epilepsy (Ben-Menachem et al, 1994; Handforth et al, 1998). Low-dose stimulation (intensity, number of pulses per day) served as the control in comparison to high stimulation. In this difficult to treat population, seizure frequency decreased $28-31 \%$ in the high stimulation group compared to baseline whereas it dropped $11-15 \%$ in the low stimulation group.

Unfortunately, few patients are able to stop their anticonvulsant medications although many are able to reduce the number of daily medications. This is clinically important in childhood epilepsy as many children experience deleterious cognitive side effects from the anticonvulsants (Ferrie and Patel, 2009; Shahwan et al, 2008).

Long-term follow-up studies have shown that the time course to respond to VNS is gradual, with continued improvement up to 1 year and then stabilization of effect. There appears to be no tolerance to VNS. The patient with the longest exposure to VNS has had the system operating for 17 years. VNS has assumed a small but significant role in epilepsy practice for those patients who have tried and failed two anticonvulsants.

VNS became available for use in Europe in 1994 and was given an FDA indication for epilepsy in the United States in 1997.

In 1997 one of the authors (MSG), along with John Rush, Harold Sackeim, and later Lauren Marangell, began an initial pilot study of VNS for patients with treatmentresistant depression (TRD) (Rush et al, 2000; Sackeim et al, 2001c). Several lines of evidence suggested that VNS might be helpful in patients with depression, including anecdotal reports of mood improvement in VNS implanted epilepsy patients and functional imaging studies showing that VNS increased activity in several regions of the brain thought to be involved with depression (Henry et al, 1998). This openlabel study with 59 patients with TRD showed good results $-30 \%$ response rate and $15 \%$ remission rate at 10 weeks. Even more encouraging were the extended results (Marangell et al, 2002; Nahas et al, 2005). Patients continued to improve long after the acute phase of the trial. Patients were clinically better at 1 year than they were at 3 months. This pattern is unusual in the treatment of depression, especially in a difficult to treat cohort with prior tolerance to antidepressants (Rush et al, 2006a, b). A recent European trial found slightly better results, but with the same side effects and time course of response (Schlaepfer et al, 2008).

A pivotal multicentered, randomized, double-blinded trial of VNS was not as encouraging. In this underpowered trial, active VNS failed to statistically separate from sham treatment. The response rates for the acute treatment of TRD were $15 \%$ for active treatment and $10 \%$ for sham treatment (Rush et al, 2005a).

A parallel but nonrandomized group was also studied and compared with those patients who received VNS in the pivotal trial above. Thus, one group received the addition of VNS and the other received 'treatment as usual' (Rush et al, 2005b). They were followed for 12 months during which time both groups received similar treatment (medications and ECT) except for the VNS difference. At the end point the response rates were significantly different: $27 \%$ for the VNS group and $13 \%$ for the treatment as usual group (George et al, 2005).

The FDA considered all these studies when evaluating VNS for depression. They were most impressed with the long-term enduring benefits for this difficult to treat population (George et al, 2005). In 2005, they approved VNS for patients with chronic or recurrent depression, either unipolar or bipolar, with a history of failing to respond to at least four antidepressant trials. As VNS is FDA approved for TRD in the absence of Class I evidence of efficacy, insurance companies have resisted reimbursing the implant. Thus, currently VNS is not making a large clinical impact for depression treatment and the field awaits a much-needed adequately powered randomized controlled trial (RCT), which unfortunately has not been started because of financial concerns on the part of the manufacturer.

It is disappointing that the overall response rate to VNS plus medications at 1 year is less than $50 \%$, as it is costly and requires a surgical implantation. However, many studies are now showing that patients with TRD have poor outcomes to traditional medication treatment (Fekadu et al, 2009; Rhebergen et al, 2009; Rush et al, 2006a, b; Ten Doesschate et al, 2009; Trivedi et al, 2006; Yiend et al, 2009). Attempts to predict who is more likely to respond to VNS have not been successful.

There are several other potential VNS clinical applications, reasoning from the known role of the vagus, including obesity (Roslin and Kurian, 2001), craving (Bodenlos et al, 2007), pain (Borckardt et al, 2006a, 2005), traumatic brain injury (Colombo et al, 2008; Neese et al, 2007; Ottani et al, 2009), and anxiety (George et al, 2008b). These small sample size trials all suggest potential efficacies in these domains but RCT are needed. 


\section{TRANSCRANIAL MAGNETIC STIMULATION}

\section{Description of Method}

Transcranial magnetic stimulation involves inducing an electrical current within the brain using pulsating magnetic fields that are generated outside the brain near the scalp. The essential feature is using electricity to generate a rapidly changing magnetic field, which in turn produces electrical impulses in the brain. A typical TMS device produces a fairly powerful magnetic field (about $1.5-3 \mathrm{~T}$ ), but only very briefly (milliseconds). TMS is not simply applying a static or constant magnetic field to the brain. By 1820 scientists had discovered that passing an electric current though a wire induces a magnetic field. In 1832, Michael Faraday showed that the inverse was also true-passing a wire through a magnetic field generates an electrical current (Faraday, 1965). Thus, a changing magnetic field can generate electrical current in nearby wires, nerves, or muscles. A static magnet will not generate a current. For most TMS applications, it likely is the electricity induced from the pulsating magnet, and not the magnetic field itself, which produces neurobiological effects.

In 1959, Kolin and his colleagues showed that a fluctuating magnetic field could stimulate a peripheral frog muscle in preparation (Kolin et al, 1959). However, it was not until 1985 that the modern era of TMS started. That year Anthony Baker in Sheffield, England described the use of a noninvasive magnetic device resembling modern TMS instruments (Barker et al, 1985). The device was slow to recharge and quick to overheat, but it was able to stimulate spinal cord roots, and also superficial human cortex.

TMS requires a unit to store and deliver a charge (called a capacitor), and an electromagnetic coil (typically round in the shape of a doughnut or two round coils side-by-side and connected in a figure eight) (see Figure 2). A system can be cumbersome (resembling a small refrigerator), although some have shown that the entire system could be made portable and weigh less than $20 \mathrm{lbs}$ (Epstein, 2008; Huang et al, 2009). The devices are regulated by the FDA for general safety, and most machines have FDA approval for sale in the US. They are also then regulated with respect to the ability to advertise their therapeutic use in a particular disorder. In the United States a device manufactured by Neuronetics was approved by the FDA in 2008 for treating depression (O'Reardon et al, 2007).

Early TMS devices only emitted a single, brief pulse. Modern devices can generate a rapid succession of pulses, called repetitive TMS (rTMS). These devices are used for behavioral research or clinical treatments and can discharge on and off for several minutes. For example, the typical treatment for depression is a $20-40 \mathrm{~min}$ session, 5 days a week for 4-6 weeks. To keep the patient still and the device correctly placed, the patient reclines in a chair and the device is held securely against their head while they are awake and alert without needing anesthesia.
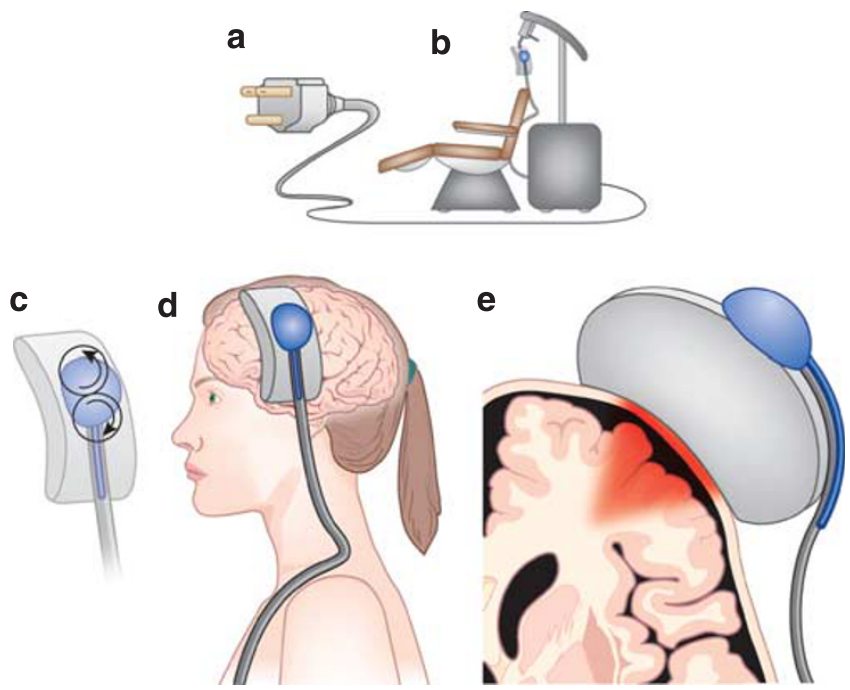

Figure 2. Transcranial magnetic stimulation (TMS). Current from the wall (a) is used to charge a bank of large capacitors (b). These capacitors send a pulsing electrical current to the coils (c) resting on the scalp (d). The powerful but brief electrical current in the coil creates a transient magnetic field, which passes unimpeded through the skin and skull and results in electrical impulses in neurons in superficial cortex under the coil (e). Depending on the type of cell that is engaged, this then results in secondary transynaptic effects. (Reprinted with permission from APPI, from Higgins and George (2008)).

The TMS coil generates a magnetic field impulse that can only reach the outer layers of the cortex (Davey et al, 2004). The main effect of the impulse only penetrates $2-3 \mathrm{~cm}$ below the device (Roth et al, 1994; Rothwell et al, 1999). However, a deep TMS device has been invented and is in early clinical trials for depression and several other indications (Roth et al, 2002, 2005).

When the TMS device produces a pulse over the motor cortex, descending fibers are activated and volleys of electrical impulses descend through connected fibers into the spinal cord and out to the peripheral nerve where it can ultimately cause a muscle to twitch. The minimum amount of energy needed to produce contraction of the thumb (abductor pollicis brevis) is called the motor threshold (MT) (Fitzgerald et al, 2006; Fox et al, 2006; Sacco and Thickbroom, 2009). As this is so easy to generate, and varies widely across individuals, the MT is used as a measure of general cortical excitability and most TMS studies (both research and clinical) report the TMS intensity as a function of individual MT (and not as an absolute physical value) (Di Lazzaro et al, 2008). Although this convention has helped in making TMS safer, it is severely insufficient, in that it is referenced only to each machine, and thus is not a universal number. Future work is focusing on more universal, constant, measures of the magnetic field delivered.

In general with TMS, a stronger, more intense pulse results in more activation of the CNS tissue, and a wider area of activation. The circumstance with frequency is more complex. In general, frequencies of less than 1 per second $(<1 \mathrm{~Hz})$ are inhibitory (Hoffman and Cavus, 2002). This 
may be because low-frequency TMS more selectively stimulates the inhibitory GABA neurons, or this frequency is LTD like. Conversely, higher frequency stimulation is behaviorally excitatory (Ziemann et al, 2008). However, high-frequency TMS over some brain regions can temporarily block or knockout the function of that part of the brain (Epstein et al, 1996; Pascual-Leone et al, 1991).

A handheld device is being developed and studied as a treatment to interrupt migraine headaches (Neuralieve). The device delivers a single large pulse. When the patient experiences the aura phase of an impending headache they hold the device to the back of their head and direct the pulse toward the occipital cortex (Ambrosini and Schoenen, 2003; Clarke et al, 2006).

\section{Putative Mechanisms of Action}

TMS can produce different brain effects depending on the brain region being stimulated, the frequency of stimulation, the use parameters (intensity, frequency, duty train), and whether the brain region is engaged or 'resting'. Thus, it is difficult to review a single 'mechanism of action' for TMS. However, in general, a single pulse of TMS over a cortical region, such as the motor cortex, causes large neurons to depolarize. That is, the powerful transient magnetic field induces current to flow in neurons in superficial cortex (induced current). Both modeling and simple testing have shown that the fibers that are most likely to depolarize are those that are perpendicular to the coil, and are bending within the gyrus (Amassian et al, 1992, ; Lisanby et al, 1998a, b). Some lower TMS intensities do not cause large neuron depolarization, but can still affect resting membrane potentials and thus alter brain activity and behavior. The most striking positive phenomena that TMS can produce are motor twitches (thumb, hand, arm, or leg movement) when applied over motor cortex, or 'phosphenes' when TMS is placed over the occiput. To date TMS cannot produce acute memories, thoughts, or sensations or percepts apart from the scalp sensation of the coil.

rTMS can produce measurable effects lasting for minutes to hours after the train. In general, rTMS at frequencies greater than $1 \mathrm{~Hz}$ are excitatory, and less than $1 \mathrm{~Hz}$ inhibitory. One particular TMS sequence builds directly from the neurobiological studies of LTP and LTD, and is called theta burst as it has short bursts of TMS at theta frequencies (Di Lazzaro et al, 2005; Stagg et al, 2009).

TMS over some cortical regions can produce a transient disruption of behavior. This is most striking when the coil is placed over Broca's area and one can produce a transient expressive aphasia. Much interest involves whether TMS can produce short-term or even longer-term changes in plasticity (Ziemann et al, 2008). Simple studies in motor and visual systems clearly indicate the potential for this approach (Miniussi et al, 2008), which is now being applied in studies of poststroke recovery and other forms of rehabilitation (Hummel et al, 2008; Pape et al, 2009).
Coupling TMS with electrophysiological measures allows one to use TMS as a measure of motor cortex excitability, and then measure how behavior, medications, or other interventions might change excitability. Several groups are using this TMS excitability measurement technique to investigate new CNS-active compounds (Li et al, 2009, 2004; Paulus et al, 2008; Ziemann et al, 2008).

Coupling TMS with imaging (PET, SPECT, fMRI, or BOLD fMRI) allows one to directly stimulate circuits and then image the resultant changes (George et al, 2007; Siebner et al, 2009). With respect to the neuropsychiatric uses of TMS for depression or pain, at a molecular level TMS is known to have similar effects as those seen with $\mathrm{ECT}$, for example, increased monoamine turnover, increased Brain-Derived Neurotrophic Factor, and normalization of the hypothalamic-pituitary-adrenal axis.

The initial use of daily prefrontal TMS to treat depression was based on the theory that clinical depression involved an imbalanced relationship between prefrontal cortex and limbic regions involved in mood regulation (insula, cingulate gyrus, amygdala, and hippocampus)(George et al, 1994). There is only limited direct support that this is occurring, although recent work by Maier and colleagues directly supports the causal role of medial prefrontal cortex in mitigating and reversing chronic learned helplessness. Stimulatory fibers from PFCx are critical in this model (Baratta et al, 2007; Christianson et al, 2008a, b; Hutchinson et al, 2008).

\section{Safety}

In general, TMS is regarded as safe and without enduring side effects. There have been no reported lasting neurologic, cognitive, or cardiovascular sequelae. However, TMS can alter brain function and is a relatively new technology so vigilance is required. The interested reader should read the results from an earlier international conference on TMS safety (Wassermann, 1997). An update has been drafted following another international meeting and should be available within the next 6 months.

Inducing a seizure is the primary safety concern with TMS. There have been less than 20 reported seizures induced with TMS, with a sample size of several thousand. The risk is less than one half of $1 \%$. Most of these patients were healthy volunteers without a history of epilepsy. Fortunately, there are no reports that the individuals affected experienced recurrence. In addition, all of the seizures occurred during TMS administration when the patient was sitting down and near an investigator. In addition, all of the seizures were self-limited without needing medications or other interventions. Published safety tables concerning the proper intensity, frequency, and number of stimuli help minimize the numbers of seizures(Wassermann, 1997). Of the reported cases the majority were receiving TMS to the motor cortex - the most epileptogenic region of the cortex. Additionally, most (but not all) were receiving trains of stimulation outside of 
suggested limits. These cases suggest that TMS induced seizures will remain a small but significant adverse event even in patients without histories of seizures and even when TMS is used within suggested guidelines.

Studies in rabbits as well as some human studies suggest that TMS can cause hearing loss and subjects, patients, and operators should wear earplugs (Counter et al, 1990; Loo et al, 2001). One patient reported a temporary hearing loss after TMS. In light of this an extensive study of auditory threshold was conducted before and after 4 weeks of TMS in over 300 patients. No changes were found. However, patients should wear earplugs when receiving TMS.

Headaches are the most common complaint after TMS, however, there was no difference in headache frequency between sham and control in a recent large trial (O'Reardon et al, 2007). Repeated analysis of neurocognitive functioning of TMS patients has not found any enduring negative effects from the procedure (Avery et al, 2008; Little et al, 2000). After a session, patients or subjects are able to drive home and return to work.

\section{Research Uses}

Space does not permit a thorough overview of TMS research uses, other than to highlight the active areas. TMS can be used as a measure of cortical excitability, and has been used to investigate medication effects, emotional states, plasticity in learning and stroke recovery, sleep (Massimini et al, 2007; Tononi and Koch, 2008), and in a host of disease states. TMS can be combined with brain imaging to directly stimulate circuits and image the resultant changes (see Figure 3). When precisely applied over critical brain regions, TMS can help causally determine whether a brain region is involved in a behavior, and how information flows through the brain during a task (Figure 4). There is much excitement, but little hard evidence, that TMS might be used to actually augment task performance, memory formation, or recovery from injury.

\section{Clinical Studies}

Largely because of its noninvasiveness, TMS has been investigated in almost all neuropsychiatric conditions. Until only recently, there has not been a TMS industry to promote or perform this work and thus much of the clinical work has been single site and nonindustry funded, with relatively small sample sizes.

Depression has been the most widely studied condition with TMS. Three initial studies from Europe used TMS over the vertex as a potential antidepressant (Grisaru et al, 1994; Hoflich et al, 1993; Kolbinger et al, 1995). In the US, George, Wassermann, and Post performed initial safety studies in healthy controls, an open study, and then a double-blind controlled trial of TMS for 2 weeks (George et al, 1997, 1995, 1996). This work has now dramatically grown, but without much change in many of the initial treatment choices (coil location, frequency, dosing). There have now been several a

"Online" approach:

concurrent TMS and neuroimaging

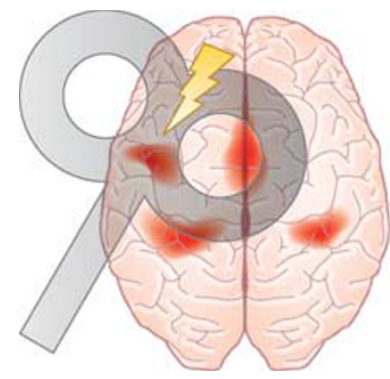

b

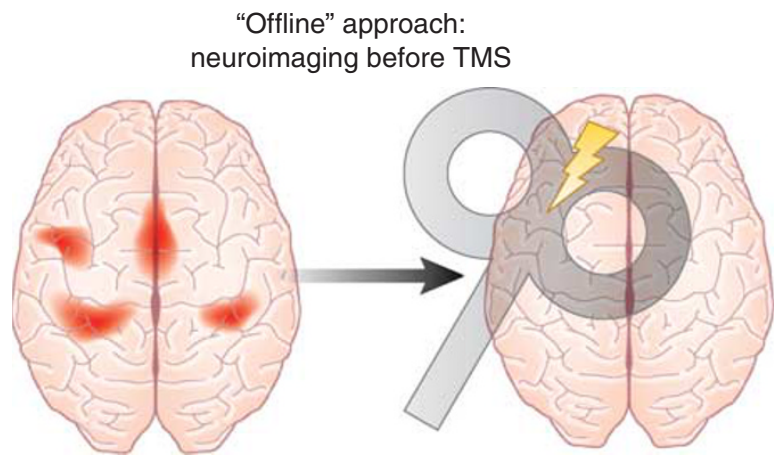

c

"Offline" approach: TMS before neuroimaging

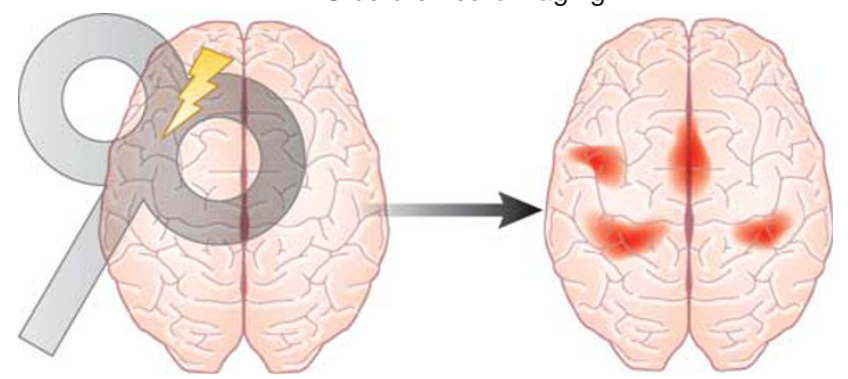

Figure 3. Brain stimulation and imaging. The combination of brain imaging with brain stimulation allows for more direct examination of the role of circuit activity in brain behavior relationships. Historically most brain imaging has been relatively passive, and changes in a circuit occur along with a behavior, but causality is not known. By combining actual stimulation with imaging one can move a step closer to causal statements, as well as prepare the stage for potential clinical translation and therapeutic uses of brain stimulation approaches. In general, one can image simultaneously with stimulation (a), or one can use the brain imaging result (structural or functional or some combination) to guide the placement of the brain stimulation (in this case TMS) (b). Finally, one can stimulate a region with TMS or tDCS, produce brain changes, and then use brain imaging to examine changes in circuit behavior (c). (Reprinted with permission from Elsevier and adapted from Siebner et al (2009)).

meta-analyses of the procedure (Ridding and Rothwell, 2007). A recent meta-analysis of rTMS for depression examined 25 published sham-controlled studies (Mitchell and Loo, 2006). The authors concluded that left prefrontal TMS provided statistical superiority over sham treatment for patients with depression. However, they concluded that the clinical benefits are marginal in the majority of reports and there is still considerable uncertainty concerning the 

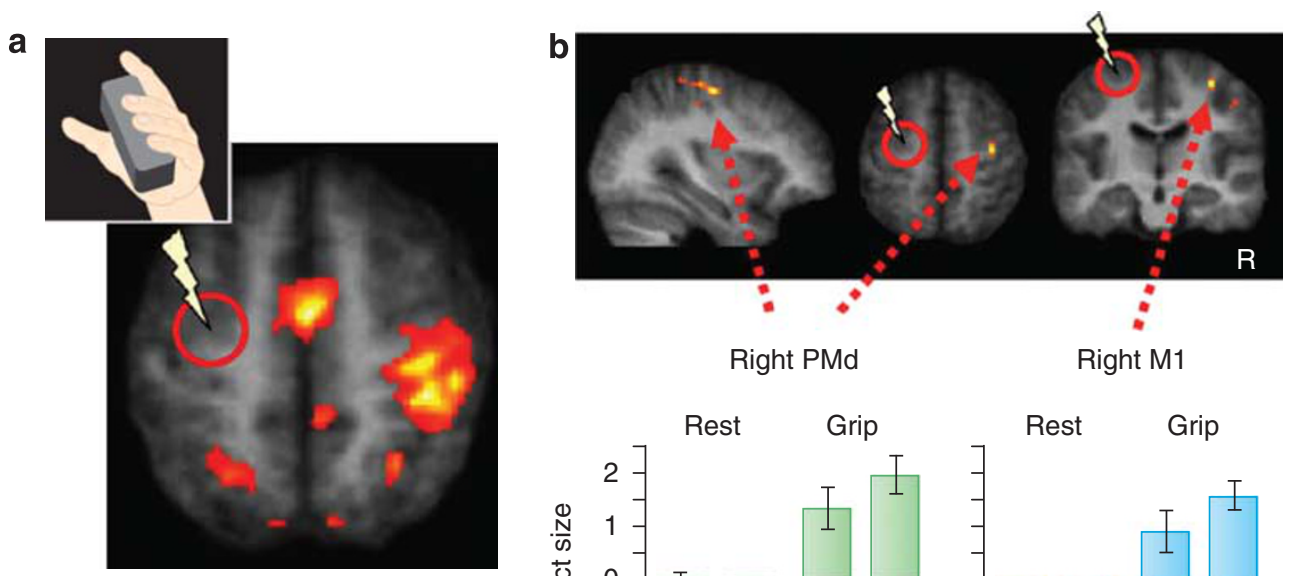

Right PMd

Right M1

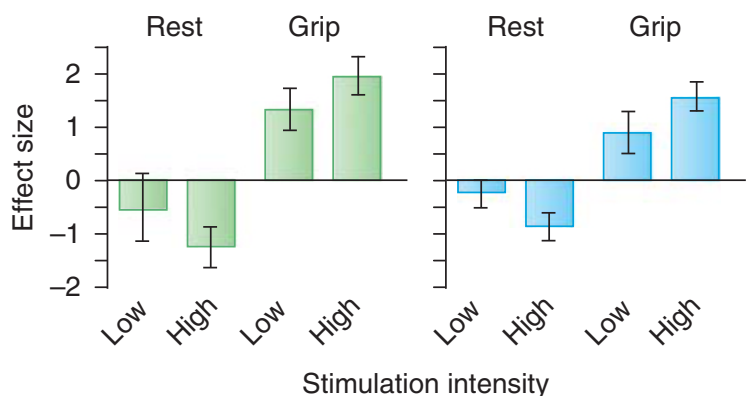

Figure 4. State-dependent interregional interactions evoked by transcranial magnetic stimulation (TMS) interleaved with fMRI. Some groups can actually use TMS within an MRI scanner (Bohning et al, 1998). These images show the (a) main effect of left hand grip, irrespective of TMS stimulation intensity. This illustrates how one can obtain blood-oxygenation-level-dependent (BOLD) activation maps during concurrent application of TMS pulses (five pulses, $11 \mathrm{~Hz}$ ) inside a magnetic resonance image (MRI) scanner. (b) Task-state-dependent effects of TMS on causal interactions in the human motor system. At rest, TMS applied to the left dorsal premotor cortex (PMd) increased activity in contralateral PMd and primary motor cortex (M1) at high stimulation intensity (110\% of resting motor threshold), compared with stimulation at a lower control intensity (70\% active motor threshold). In contrast, this effect was reversed during a simple motor task that activated right PMd and M1. Now high-intensity stimulation increased task-related activity, compared with lower intensity stimulation. The results show how TMS can causally affect activity in contralateral regions, and that these influences are dependent on the activation state of these regions (adapted from Bestmann et al (2003) and reprinted with permission from Elsevier and Siebner et al (2009)).

optimal stimulation parameters. Two recent positive metaanalyses suggest that the overall effect size with TMS in major depression is at least as good as that of standard pharmacotherapy (Lam et al, 2008; Schutter, 2008). Those clinical features that appear to be associated with greater response include younger age, lack of refractoriness to antidepressants, and no psychotic features (Avery et al, 2008).

The largest multisite trial to date, which resulted in FDA approval, was by Neuronetics. They sponsored a doubleblind, multisite study of 301 medication-free patients with major depression. Patients were randomized to active TMS or sham treatment, which they received for 4-6 weeks (O'Reardon et al, 2007). There was some controversy about the results of the trial. Before conducting the experiment, the company chose a continuous variable, the change from baseline on the Montgomery-Asberg Depression Rating Scale (MADRS), as the primary outcome measure (and did not tell investigators in the field) while using the Hamilton Rating Scale as the entry criteria. Unfortunately, at 6 weeks the continuous measured MADRS change from baseline for the active treatment group was not quite statistically different from the control group: $p=0.058$. The Hamilton Depression Rating Scale scores, considered secondary outcome measures, were indeed superior for those in the active treatment group. The company argued, successfully for the publication, that they should be able to exclude six subjects with entry MADRS scores that were very low and could not reflect clinical improvement. Thus, the manuscript was published as a positive trial but the FDA initially rejected the application, and only agreed for approval after reviewing response data on subgroups. As there was such a large effect seen in those who were less treatment resistant, the FDA labeling is for the treatment of MDD in adult patients who have failed to achieve satisfactory improvement from one prior antidepressant treatment at or above the minimal effective dose and duration in the current episode. Note that in clinical practice, only about one in four treatment trials meets criteria for minimal dose and duration, so this translates in a clinical practice to patients with a moderate level of treatment resistance (Dew et al, 2005; Joo et al, 2005; Oquendo et al, 2003).

These mixed results reflect the current status of TMS for depression. Most agree that daily left prefrontal TMS for several weeks has antidepressant effects and is safe and well tolerated. It will likely be an ideal treatment for some patients. However, the efficacy data in trials to date are not as robust as some would like and many await the results of larger ongoing trials and better understanding of the mechanisms of action. For example, a large European trial failed to find a statistically significant difference, but likely used an active sham condition as well as examined TMS as 
an augmentation rather than stand-alone treatment (Herwig et al, 2007). The NIH has funded a large multisite trial in depression with results due in late 2009 and the VA has launched a large cooperative study of daily left prefrontal TMS in depressed veterans.

One recent development in terms of TMS positioning has highlighted that better understanding of the TMS methods used will likely boost clinical antidepressant efficacy. The early NIMH studies used a rough measurement technique known as the 5 -cm rule to place the TMS coil roughly over the prefrontal cortex (George et al, 1997, 1995, 1996). As the location of the motor strip varies between individuals, and skull size (hat size) also varies, this simple rule results in a large variation of actual location on scalp. It became obvious that this was an insufficient technique, but was nevertheless used in most trials, including the one for FDA approval (Herwig et al, 2001). One study suggested that the $5-\mathrm{cm}$ rule resulted in $30 \%$ of patients being treated over supplementary motor area rather than prefrontal cortex. Two retrospective analyses of clinical trials in which brain imaging was performed to document the coil location have independently confirmed that a coil position that is anterior and lateral is associated with a better clinical response to active but not sham TMS (Herbsman et al, 2009). An Australian group has performed a RCT and a more anterior and lateral location did indeed produce superior antidepressant response (Fitzgerald et al, 2009). These findings suggest that the TMS effect is not nonspecific, and that the location of the coil clearly matters, even within broad boundaries of a specific lobe. It is not clear whether individualized location will be needed or used, or whether general algorithms will suffice for most patients.

Auditory hallucinations are part of the positive symptoms of schizophrenia. These types of hallucinations are believed to result from aberrant activation of the language perception area at the junction of the left temporal and parietal cortices (Higgins and George, 2007). Low-frequency TMS has been used to potentially inhibit this area in patients with schizophrenia and provide relief from auditory hallucinations. A recent meta-analysis examined the efficacy of lowfrequency TMS as a treatment of resistant auditory hallucinations in schizophrenia (Aleman et al, 2007). Ten sham-controlled studies have incorporated 212 patients. Their review concluded that TMS was effective in reducing auditory hallucinations. Unfortunately, TMS had no effect on other positive symptoms or the cognitive deficits of schizophrenia. Larger studies are needed to definitely establish the efficacy, tolerability, and utility of TMS for schizophrenia.

There have been four RCTs of using intermittent daily prefrontal TMS to treat negative symptoms in patients with schizophrenia. Only one of these studies was positive.

Tinnitus is a common, often disabling disorder, for which there is no adequate treatment. As many as $8 \%$ of adults over 50-years old suffer from tinnitus that can often be quite distressing. Recent functional imaging studies have identified increased activity in the auditory cortex in patients with tinnitus. Low-frequency TMS offers a possible mechanism to inhibit the overactive auditory cortex that may be producing tinnitus. Several small controlled trials from one research group in Germany have produced impressive results (Langguth et al, 2008). Larger, multicenter studies are needed to see if these positive effects can be replicated.

Numerous small controlled studies have evaluated the utility of TMS in patients with pain. Multiple sites have been tested including prefrontal cortex, motor cortex, and parietal cortex(Andre-Obadia et al, 2006; Lefaucher et al, 2001; Lefaucheur, 2004; Lefaucheur et al, 2001; Pridmore and Oberoi, 2000; Rollnik et al, 2003). In general, TMS provides effective pain relief in these different locations in diverse pain conditions. Unfortunately, the effect of TMS on pain only lasts for a short duration. Consequently, the utility of TMS as a practical treatment for chronic pain conditions has yet to be established.

Recent studies suggest TMS may have some utility in managing acute pain. In two different studies of patients recovering from gastric by-pass surgery, $20 \mathrm{~min}$ of real or sham TMS was administered to the prefrontal cortex of every patient. Then their use of self-administered morphine was followed over the next $48 \mathrm{~h}$. Those receiving real TMS used $40 \%$ less morphine in the next $24 \mathrm{~h}$, with the majority of the reduction occurring in the first $8 \mathrm{~h}$ after TMS (Borckardt et al, 2008b, 2006b).

The handheld device, mentioned above, is being studied as a treatment for migraine headaches. Preliminary results have been encouraging. Larger studies are underway.

Following an ischemic event to the motor cortex, the brain attempts to reorganize the damaged networks. Indeed, the extent of reorganization correlates with the clinical recovery of motor function. TMS may accelerate the reorganization process and therefore enhance recovery (Hummel et al, 2008; Miniussi et al, 2008; Pape et al, 2009). It is unclear which types of TMS may be beneficial in stroke recovery. High-frequency TMS to the affected area may enhance reorganization. Alternatively, low-frequency TMS to the opposite, intact hemisphere is believed to reduce the interference from the nonstroke side. Some believe that too much input from the unaffected side of the brain impedes recovery. Reducing excitability with low-frequency TMS may enhance recovery.

Ridding and Rothwell recently reviewed the studies of TMS in stroke recovery. Although the total number of patients in controlled trials was only 87, the results were encouraging. Clearly, larger studies are needed, but it appears that TMS might be able to improve the natural healing process after a stroke (Kew et al, 1994; McKay et al, 2002; Ridding and Rothwell, 1995, 2007).

Theoretically low-frequency TMS could be used to treat cortical epilepsy. Early studies showed that TMS could reduce EEG epileptiform abnormalities. Initial case studies were positive. A controlled study of daily TMS by Theodore et al (2002) over the cortical site of seizures for 1 week found a statistically significant reduction in seizures. However, the authors concluded that TMS treatment was 
not clinically significant. More recently, in another controlled trial Cantello et al (2007) concluded that 'active' rTMS was no better than placebo for seizure reduction. Thus, the idea of using inhibitory doses of TMS to calm cortical targets is intriguing. However, the controlled trials to date have not been as successful.

\section{TRANSCRANIAL DIRECT CURRENT STIMULATION}

\section{Description of Method}

Transcranial direct current stimulation (tDCS) is perhaps one of the simplest ways of focally stimulating the brain. Similar techniques were practiced almost immediately after electricity was 'discovered' in the late 1880 s. Passing a direct current through muscle, or the brain, was in vogue in Europe. For example, one of Charcot's residents, Georges Duchenne de Boulogne, traveled around Paris with a small battery and passed electricity through patients' muscles, examining the effects on numerous disorders and using it to better understand muscle-nerve innervations, particularly in the muscular dystrophies (George, 1994). Others began applying direct current through the brain. Owing to lack of benefits, this was largely dropped as a treatment in Europe and the US.

For reasons that are not clear, tDCS remained an area of active research in Russia during the 1940s up until the present time. It was sometimes called 'electrosleep therapy' as patients would sometimes nap or sleep during the 30-min treatments (Gomez and Mikhail, 1978). Most of the tDCS done in Russia was not delivered in clinical trials, and was largely anecdotally used for the treatment of alcoholism, pain, depression, or a combination (Feighner et al, 1973).

Dr Walter Paulus and his group in Gottingen, Germany have led a recent resurrection of this technology, and there is now active investigation of tDCS, with over 100 articles in the last 10 years in peer-reviewed journals (Paulus, 2003). Clearly, tDCS has an affect on the brain-it can boost cortical excitability and improve memory in healthy people (Boggio et al, 2007, 2006). Whether these effects can be used therapeutically remains to be determined (George et al, 2009; Nitsche et al, 2008).

Quite simply, tDCS involves passing a weak (usually $\leqslant 1 \mathrm{~mA}$ ) direct current through the brain between two electrodes. The current enters the brain from the anode, travels through the tissue, and exits out the cathode. Some researchers refer to this as either cathodal tDCS or anodal tDCS depending on which electrode is placed over the region that is being modified (Figure 5).

The administration of tDCS is relatively easy. Many researchers simply use damp sponges as the electrodes. These can be placed anywhere on the scalp and are held in place with an elastic headband.
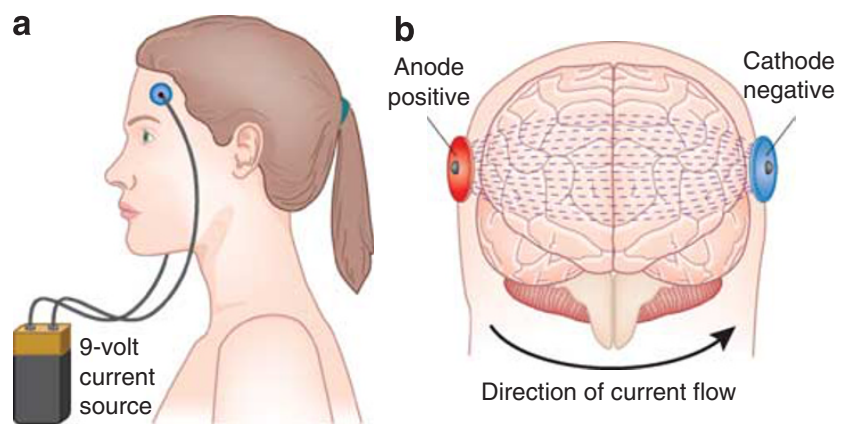

Figure 5. Transcranial direct current stimulation (tDCS). A tDCS device uses an anode and cathode connected to a direct current source much like a $9 \mathrm{~V}$ battery (a). The direct current passes through the intervening tissue, with some shunting through the skull but much of it passes through the brain and changes resting electrical charge, particularly under the cathode (b). Reprinted with permission from APPI, from Higgins and George (2008).

\section{Putative Mechanisms of Action}

Exactly what happens to the brain with tDCS remains unknown. However, experiments with animals, humans, and even direct recordings from individual neurons give a general idea. Remember that the cathode (which is negative) is where the electricity exits the brain. Thus, there is a buildup of negative charge under the exiting cathode as the electrons pool to leave through the exiting electrode. A smaller exiting cathode can produce a more focal delivery of charge to a brain region, as more charge lines up underneath the exit. Thus, one can shape or influence the size of the brain region being affected by changing the size of the cathodal electrode (smaller size is more focused) (Borckardt et al, 2008a) or by changing the size and location of the anodal electrode (Datta et al, 2008; Nitsche et al, 2007).

The behavioral effects of what happens under the exiting cathode are not necessarily as simple as one would hope. In most studies the area under the anode is more active (or excited) and the area under the cathode more inhibited (Radman et al, 2008). For example, stimulation of the motor regions produces such results and this is being exploited as a possible treatment for stroke. There has been an unfortunate confusion of terms, 'anode' and 'cathode' in some of the earlier work but this is getting clarified in the literature with better descriptions of exact methods.

However, the brain is enormously complex and there are studies where the brain region under the anode is behaviorally inhibited. For example, in one study, examining the latency of a visual evoked response, $10 \mathrm{~min}$ of anodal tDCS reduced VEP amplitudes, whereas 10 min of cathodal tDCS increased amplitudes for several minutes following stimulation (Accornero et al, 2007). Thus, in this study, there was behavioral inhibition under the anode and excitation under the cathode. It seems that the different regions of the brain with different morphology, layering, and cellular composition can have different responses to direct current stimulation. 
As the human head is a poor conductor of electricity, tDCS (and ECT) are inefficient at stimulating the brain, as at least $50 \%$ of the current is lost to the surrounding tissue. Thus, one can use markedly less electricity with direct invasive techniques, such as DBS, or with TMS (where the magnetic field passes through the skull).

Finally, as with all stimulation techniques, the ability to induce enduring effects, beyond the time of administration, is essential for practical clinical applications. With tDCS, it seems that the focal and behavioral changes can persist for some time at least after the electrodes are removed. In studies of tDCS on motor cortex, for example, tDCS induced inhibition or excitation can last for several minutes to an hour or so (Fregni et al, 2006). Whether therapeutic changes can endure for weeks or months remain to be determined.

\section{Safety}

Side effects of tDCS depend on the placement of the electrode, whether it is anodal or cathodal, the intensity of the stimulation, and the length of time the patient is treated (Poreisz et al, 2007). In the older prefrontal treatment literature, skin burns could occur, and some patients felt uncomfortable or even had dizziness. There are now several case reports of skin lesions or burns following tDCS (Palm et al, 2008).

Paulus and colleagues reported their results in 567 patients and subjects who had received tDCS in challenge studies over the motor, parietal, or occipital cortex (Poreisz et al, 2007). Remarkably, no patient requested the stimulation be terminated. About $70 \%$ of subjects noticed a mild tingling sensation under the electrode; $1 / 3$ of subjects felt fatigue after treatment and $1 / 3$ also felt 'itching' under the electrode. Headache (11\%), nausea (3\%), and insomnia (1\%) were also found, but less frequently.

\section{Research and Clinical Studies}

Much of the most recent work with tDCS dealt with the behavioral effects of tDCS stimulation on healthy controls. Although it is beyond the scope of this chapter to review exhaustively these more basic behavioral studies, it is clear that tDCS can focally excite or inhibit the brain. This impressive and growing body of research strongly suggests that there are perhaps clinical uses of tDCS yet to be discovered.

Numerous small studies with healthy volunteers have shown that tDCS can enhance motor function and control. The next logical step is to apply the technique to patients whose motor control has been damaged because of a stroke. The unique qualities of tDCS offer possibilities beyond just stimulating the damaged tissue. Some research suggests that constraining the unaffected, healthy side of the brain actually improves healing. For example, constraining the good arm and forcing the patient to use the impaired arm improves recovery after a stroke affecting the upper limb.
Theoretically, tDCS could be able to mimic this therapeutic process. That is, one could excite the damaged side while inhibiting the healthy side. When the anode is placed over the injury, it should excite the neurons beneath it. Likewise, if the cathode is placed over the healthy side, it should provide some inhibition of those neurons. In summary, however, the work in stroke is still preliminary without large clear effects in well-conducted sham-controlled trials (Alonso-Alonso et al, 2007; Fregni and PascualLeone, 2007; Hummel et al, 2008; Nitsche et al, 2008; Schlaug and Renga, 2008a; Schlaug et al, 2008b).

As with all of the new stimulation techniques, there have been groups trying out the technology in many neuropsychiatric disorders. Single site small sample studies have suggested some positive effects of tDCS in pain, migraine, fibromyalgia, depression, and epilepsy. None of the studies were large or multisite, and the sample sizes have been small (George et al, 2009). Further work is needed to see if these early promising studies replicate.

Thus, tDCS is an exciting new tool, but there are no clinically useful applications at the moment. tDCS, like many of the stimulation techniques, followed the interesting pattern of discovery, overuse, misuse, and then a reawakening with more modern approaches. tDCS likely will be clinically useful in the near future for some conditions, especially when coupled with pharmacological and behavioral approaches to reshaping circuit behavior in health or disease.

\section{OTHERS}

The field of brain stimulation is rapidly growing and transforming. For example, in a recent issue of science two reports suggest that more invasive DBS might be replaced with simpler surface-based approaches to stimulation (Gradinaru et al, 2009; Fuentes et al, 2009).Thus, even spinal cord stimulators, electroacupuncture, or simple TENS units might become more widely used as the field learns more about the underlying neurobiology of circuits, and how to interact with them. The field is evolving rapidly (George and Sackeim, 2008a; Higgins and George, 2008; Sackeim and George, 2008).

We have listed the current known techniques discussed in this volume in Table 1 , and have indicated which conditions are FDA approved.

\section{FUTURE DIRECTIONS AND CLINICAL IMPLICATIONS}

Dale's principle is clearly outdated (one neuron, one transmitter). An analogy to this outdated approach of one transmitter, one disease is also likely outdated (eg dopamine and schizophrenia). The data reviewed in this chapter and this volume clearly suggest that the near future of our field involves understanding focal pharmacology and how several neurotransmitters interact in discrete 
Table I The Major Brain Stimulation Techniques and Their FDA Approved Indications

\begin{tabular}{|c|c|c|}
\hline Device & Disease & $\begin{array}{l}\text { Current FDA } \\
\text { status }\end{array}$ \\
\hline \multirow[t]{5}{*}{ Deep brain stimulation } & Parkinsons disease & General approval \\
\hline & Dystonia & $\begin{array}{l}\text { Humanitarian device } \\
\text { Exemption approval }\end{array}$ \\
\hline & $\begin{array}{l}\text { Obsessive-compulsive } \\
\text { disorder }\end{array}$ & $\begin{array}{l}\text { Humanitarian device } \\
\text { Exemption approval }\end{array}$ \\
\hline & Epilepsy & Clinical trials underway \\
\hline & $\begin{array}{l}\text { Treatment-resistant } \\
\text { depression }\end{array}$ & Clinical trials underway \\
\hline \multirow[t]{2}{*}{ Vagus nerve stimulation } & Epilepsy & General approval \\
\hline & $\begin{array}{l}\text { Treatment-resistant } \\
\text { depression }\end{array}$ & General approval \\
\hline \multirow[t]{2}{*}{$\begin{array}{l}\text { Transcranial magnetic } \\
\text { stimulation }\end{array}$} & $\begin{array}{l}\text { Treatment-resistant } \\
\text { depression, unipolar }\end{array}$ & General approval \\
\hline & Migraine prophylaxis & Clinical trials underway \\
\hline $\begin{array}{l}\text { Transcranial direct current } \\
\text { stimulation }\end{array}$ & & $\begin{array}{l}\text { No FDA approved } \\
\text { indication }\end{array}$ \\
\hline
\end{tabular}

brain regions and circuits to drive behaviors and create disease.

This revolution in basic mechanisms of understanding at a circuit level is occurring simultaneously with an explosion of new technologies for interacting with the brain through direct and indirect stimulation. These approaches vary drastically from traditional neuropsychopharmacology, with profound differences in dosing, tolerance, and compliance. The field is just beginning to understand some of the more basic underlying principles in this new area.

The future is bright for this area as there is simultaneous growth in two areas. This review volume testifies to how the knowledge of the neurobiology of circuits is expanding. The technology of the brain stimulation methods is also in a very rapid growth phase. Over the past decade these stimulation methods have already transformed or at least significantly impacted the treatment of Parkinson's disease, epilepsy, dystonia, OCD, and depression. Hopefully, this rapid pace will continue and 10 years from now the field will be using none of the current methods, but rather another generation of brain stimulation methods honed on the knowledge flowing from basic science and imaging.

\section{DISCLOSURE}

Dr George reports no equity or other direct financial investment in any device or pharmaceutical firm. Within the past 3 years he has: served as a paid consultant to GlaxoSmith-Kline, Jazz Pharmaceuticals, Cyberonics, Neuropace, received research grants from Glaxo-Smith-Kline, Jazz Pharmaceuticals, Brainsway, served as an unpaid consultant to: Brainsonix, Brainsway, Neuronetics, NeoStim, been the editor-in-chief of a journal published by Elsevier entitled
Brain Stimulation. MUSC holds patents in the area of combining TMS with functional brain imaging. The total compensation from any company in a single year has been less than $\$ 10000$. The total combined compensation from all consulting activities is less than $10 \%$ of his university salary.

\section{REFERENCES}

(Those references marked with a * are particularly worth reading, with a note why.)

Accornero N, Li Voti P, La Riccia M, Gregori B (2007). Visual evoked potentials during direct current cortical polarization. Exp Brain Res 178: 261-266.

Aleman A, Sommer IE, Kahn RS (2007). Efficacy of slow repetitive transcranial magnetic stimulation in the treatment of resistant auditory hallucinations in schizophrenia: a meta-analysis. J Clin Psychiatry 68: 416-421.

Alonso-Alonso M, Fregni F, Pascual-Leone A (2007). Brain stimulation in poststroke rehabilitation. Cerebrovasc Dis 24(Suppl 1): 157-166.

*Amassian VE, Eberle L, Maccabee PJ, Cracco RQ (1992). Modelling magnetic coil excitation of human cerebral cortex with a peripheral nerve immersed in a brainshaped volume conductor: the significance of fiber bending in excitation. Electroencephalogr Clin Neurophysiol 85: 291-301. This is a classic in the field and helps explain which parts of which nerve fibers are excited by TMS.

Amassian VE, Quirk GJ, Stewart M (1990). A comparison of corticospinal activation by magnetic coil and electrical stimulation of monkey motor cortex. Electroencephalogr Clin Neurophysiol 77: 390-401.

Ambrosini A, Schoenen J (2003). The electrophysiology of migraine. Curr Opin Neurol 16: 327-331.

Andre-Obadia N, Peyron R, Mertens P, Mauguiere F, Laurent B, Garcia-Larrea L (2006). Transcranial magnetic stimulation for pain control. Double-blind study of different frequencies against placebo, and correlation with motor cortex stimulation efficacy. Clin Neurophysiol 117: 1536-1544.

Aston-Jones G (2004). Locus coeruleus, A5 and A7 noradrenergic cell groups. In: Paxinos G (ed). The Rat Nervous System. Elsevier Academic Press: San Diego, CA. pp 259-294.

Aston-Jones G, Ennis M, Pieribone VA, Nickell WT, Shipley MT (1986). The brain nucleus locus coeruleus: restricted afferent control of a broad efferent network. Science 234: 734-737.

Avery DH, Isenberg KE, Sampson SM, Janicak PG, Lisanby SH, Maixner DF et al (2008). Transcranial magnetic stimulation in the acute treatment of major depressive disorder: clinical response in an open-label extension trial. J Clin Psychiatry 69: 441-451

Bailey P, Bremer F (1938). A sensory cortical representation of the vagus nerve. J Neurophysiol 405-412.

Baratta MV, Christianson JP, Gomez DM, Zarza CM, Amat J, Masini CV et al (2007). Controllable versus uncontrollable stressors bi-directionally modulate conditioned but not innate fear. Neuroscience 146: 1495-1503.

*Barker AT, Jalinous R, Freeston IL (1985). Non-invasive magnetic stimulation of human motor cortex. Lancet 1: 1106-1107. This is another classic showing for the first time how TMS can actually stimulate the spine, or brain.

Ben-Menachem E, Manon-Espaillat R, Ristanovic R, Wilder BJ, Stefan H, Mirza W et al (1994). Vagus nerve stimulation for treatment of partial seizures: 1. A controlled study of effect on seizures. First International Vagus Nerve Stimulation Study Group. Epilepsia 35: 616-626.

Bestmann S, Baudewig J, Siebner HR, Rothwell JC, Frahm J (2003). Subthreshold high-frequency TMS of human primary motor cortex modulates interconnected frontal motor areas as detected by interleaved fMRI-TMS. Neuroimage 20 : 1685-1696.

Biggio F, Gorini G, Utzeri C, Olla P, Marrosu F, Mocchetti I et al (2009). Chronic vagus nerve stimulation induces neuronal plasticity in the rat hippocampus. Int $J$ Neuropsychopharmacol (CINP) 1-13.

Bodenlos JS, Kose S, Borckardt JJ, Nahas Z, Shaw D, O'Neil PM et al (2007). Vagus nerve stimulation acutely alters food craving in adults with depression. Appetite 48: 145-153.

Boggio PS, Bermpohl F, Vergara AO, Muniz ALCR, Nahas FH, Leme PB et al (2007). Go-no-go task performance improvement after anodal transcranial DC stimulation of the left dorsolateral prefrontal cortex in major depression. $J$ Affect Disord 101: 91-98.

Boggio PS, Ferrucci R, Rigonatti SP, Covre P, Nitsche M, Pascual-Leone A et al (2006). Effects of transcranial direct current stimulation on working memory in patients with Parkinson's disease. J Neurologic Sci 249: 31-38. 
Bohning DE, Shastri A, Nahas Z, Lorberbaum JP, Andersen SW, Dannels WR et al (1998). Echoplanar BOLD fMRI of brain activation induced by concurrent transcranial magnetic stimulation. Invest Radiol 33: 336-340.

Boon P, Moors I, De Herdt V, Vonck K (2006). Vagus nerve stimulation and cognition. Seizure 15: 259-263.

Borckardt JJ, Anderson B, Kozel FA, Nahas Z, Smith AR, Thomas KJ et al (2006a). Acute and long-term VNS effects on pain perception in a case of treatmentresistant depression. Neurocase 12: 216-220.

Borckardt JJ, Kozel FA, Anderson B, Walker A, George MS (2005). Vagus nerve stimulation affects pain perception in depressed adults. Pain Res Manag 10: 9-14.

Borckardt JJ, Linder KJ, Ricci R, Li X, Anderson B, Arana AB et al (2008a). Focal electrically administered therapy (FEAT): device parameter effects on stimulus perception in humans. J ECT 2009. 25(2): 91-98

Borckardt JJ, Reeves ST, Weinstein M, Smith AR, Shelley N, Kozel FA et al (2008b). Significant analgesic effects of one session of postoperative left prefrontal cortex repetitive transcranial magnetic stimulation: a replication study. Brain Stimulat 1: 122-127.

Borckardt JJ, Weinstein M, Reeves ST, Kozel FA, Nahas Z, Smith AR et al (2006b). Postoperative left prefrontal repetitive transcranial magnetic stimulation reduces patient-controlled analgesia use. Anesthesiology 105: 557-562.

Borghetti D, Pizzanelli C, Maritato P, Fabbrini M, Jensen S, ludice A et al (2007). Mismatch negativity analysis in drug-resistant epileptic patients implanted with vagus nerve stimulator. Brain Res Bull 73: 81-85.

Cantello R, Rossi S, Varrasi C, Ulivelli M, Civardi C, Bartalini S et al (2007). Slow repetitive TMS for drug-resistant epilepsy: clinical and EEG findings of a placebocontrolled trial. Epilepsia 48: 366-374.

Chae JH, Nahas Z, Lomarev M, Denslow S, Lorberbaum JP, Bohning DE et al (2003). A review of functional neuroimaging studies of vagus nerve stimulation (VNS). J Psychiatr Res 37: 443-455.

Christianson JP, Benison AM, Jennings J, Sandsmark EK, Amat J, Kaufman RD et al (2008a). The sensory insular cortex mediates the stress-buffering effects of safety signals but not behavioral control. J Neurosci 28: 13703-13711.

Christianson JP, Paul ED, Irani M, Thompson BM, Kubala KH, Yirmiya R et al (2008b). The role of prior stressor controllability and the dorsal raphe nucleus in sucrose preference and social exploration. Behav Brain Res 193: 87-93.

Clark KB, Naritoku DK, Smith DC, Browning RA, Jensen RA (1999). Enhanced recognition memory following vagus nerve stimulation in human subjects. Nat Neurosci 2: 94-98.

Clarke BM, Upton AR, Kamath MV, Al-Harbi T, Castellanos CM (2006). Transcranial magnetic stimulation for migraine: clinical effects. J Headache Pain 7: 341-346.

Colombo J, Shoemaker WC, Belzberg H, Hatzakis G, Fathizadeh P, Demetriades D (2008). Noninvasive monitoring of the autonomic nervous system and hemodynamics of patients with blunt and penetrating trauma. J Trauma 65: 1364-1373.

Counter SA, Borg E, Lofqvist L, Brismar T (1990). Hearing loss from the acoustic artifact of the coil used in extracranial magnetic stimulation. Neurology 40: 1159-1162.

Datta A, Elwassif M, Bansal V, Diaz J, Battaglia F, Bikson M (2008). A system and device for focal transcranial direct current stimulation using concentric ring electrode configurations. Brain Stimulat 1: 318

Davey KR, Epstein CM, George MS, Bohning DE (2004). Modeling the effects of electrical conductivity of the head on the induced electrical field in the brain during magnetic stimulation. Clin Neurophysiol 114: 2204-2209.

Dew RE, Kramer SI, McCall WV (2005). Adequacy of antidepressant treatment by psychiatric residents: the antidepressant treatment history form as a possible assessment tool. Acad Psychiatry 29: 283-288.

Di Lazzaro V, Pilato F, Saturno E, Oliviero A, Dileone M, Mazzone P et al (2005). Theta-burst repetitive transcranial magnetic stimulation suppresses specific excitatory circuits in the human motor cortex. J Physiol 565(Pt 3): 945-950.

Di Lazzaro V, Ziemann U, Lemon RN (2008). State of the art: physiology of transcranial motor cortex stimulation. Brain Stimulat 1: 345-362.

Dorr AE, Debonnel G (2006). Effect of vagus nerve stimulation on serotonergic and noradrenergic transmission. JPharmacol Exp Ther 318: 890-898.

Ebben MR, Sethi NK, Conte M, Pollak CP, Labar D (2008). Vagus nerve stimulation, sleep apnea, and CPAP titration. J Clin Sleep Med 4: 471-473.

Ennis M, Aston-Jones G (1988). Activation of locus coeruleus from nucleus paragigantocellularis: a new excitatory amino acid pathway in brain. J Neurosci 8: 3644-3657.

Epstein CM (2008). A six-pound battery-powered portable transcranial magnetic stimulator. Brain Stimulat 1: 128-130.

Epstein CM, Lah JJ, Meador K, Weissman JD, Gaitan LE, Dihenia B (1996). Optimum stimulus parameters for lateralized suppression of speech with magnetic brain stimulation. Neurology 47: 1590-1593.
Faraday M (1965). Effects on the production of electricity from magnetism (1831). In: Williams LP (ed). Michael Faraday. Basic Books: New York. p 531.

Feighner JP, Brown SL, Olivier JE (1973). Electrosleep therapy. A controlled double blind study. J Nerv Ment Dis 157: 121-128.

Fekadu A, Wooderson SC, Markopoulo K, Donaldson C, Papadopoulos A, Cleare AJ (2009). What happens to patients with treatment-resistant depression? A systematic review of medium to long term outcome studies. J Affect Disord 116: 4-11.

Ferrie CD, Patel A (2009). Treatment of Lennox-Gastaut Syndrome (LGS). Eur J Paediatr Neurol.

Fitzgerald PB, Fountain S, Daskalakis ZJ (2006). A comprehensive review of the effects of rTMS on motor cortical excitability and inhibition. Clin Neurophysiol 117: 2584-2596.

Fitzgerald PB, Hoy K, McQueen S, Maller JJ, Herring S, Segrave R et al (2009). A randomized trial of rTMS targeted with MRI based neuro-navigation in treatmentresistant depression. Neuropsychopharmacology 34: 1255-1262.

Foley JO, DuBois F (1937). Quantitative studies of the vagus nerve in the cat. The ratio of sensory and motor studies. J Comp Neurol 67: 49-67.

Fox PT, Narayana S, Tandon N, Fox SP, Sandoval H, Kochunov P et al (2006). Intensity modulation of TMS-induced cortical excitation: primary motor cortex. Hum Brain Mapp 27: 478-487.

Fregni F, Boggio PS, Santos MC, Lima M, Vieira AL, Rigonatti SP et al (2006). Noninvasive cortical stimulation with transcranial direct current stimulation in Parkinson's disease. Mov Disord 21: 1693-1702.

Fregni F, Pascual-Leone A (2007). Technology insight: noninvasive brain stimulation in neurology-perspectives on the therapeutic potential of rTMS and tDCS. Nat Clin Pract Neurol 3: 383-393

Fuentes R, Petersson P, Sieser WB, Caron MG, Nicolelis MAL (2009). Spinal cord stimulation restores locomotion in animal models of Parkinson's disease. Science 323: 1578.

George MS (1994). Reanimating the face: early writings by Duchenne and Darwin on the neurology of facial emotion expression. J Hist Neurosci 3: 21-33.

George MS, Belmaker RH (2006). TMS in Clinical Psychiatry. American Psychiatric Press: Washington, DC

George MS, Bohning DE, Li X, Nahas Z, Denslow S, Ramsey D et al (2007). Neuroimaging of rTMS effects on the brain. In: Marcolin M, Padberg F (eds). Transcranial Brain Stimulation in Mental Disorders. Karger: Berlin.

*George MS, Ketter TA, Post RM (1994). Prefrontal cortex dysfunction in clinical depression. Depression 2: 59-72. This first lays out the cortico-limbic imbalance reasoning that led to trials of TMS for depression.

George MS, Padberg F, Schlaepfer TE, O'Reardon JP, P.B. F, Nahas Z et al (2009). Controversy: repetitive transcranial magnetic stimulation or transcranial direct current stimulation shows efficacy in treating psychiatric diseases (depression, mania, schizophrenia, obsessive-complusive disorder, panic, posttraumatic stress disorder). Brain Stimulat 2: 14-21.

*George MS, Rush AJ, Marangell LB, Sackeim HA, Brannan SK, Davis SM et al (2005). A one-year comparison of vagus nerve stimulation with treatment as usual for treatment-resistant depression. Biol Psychiatry 58: 364373. .This manuscript describes the effects of VNS over one year, compared to treatment as usual, and shows the dismal responses with conventional treatments in TRD.

George MS, Sackeim HA (2008a). Brain stimulation, revolutions, and the shifting time domain of depression. Biol Psychiatry 64: 447-448.

George MS, Sackeim HA, Rush AJ, Marangell LB, Nahas Z, Husain MM et al (2000). Vagus nerve stimulation: a new tool for brain research and therapy. Biol Psychiatry 47: 287-295.

George MS, Ward HE, Ninan PT, Pollack M, Nahas Z, Anderson B et al (2008b). A pilot study of vagus nerve stimulation (VNS) for treatment-resistant anxiety disorders. Brain Stimulat 1: 112-121.

*George MS, Wassermann EM, Kimbrell TA, Little JT, Williams WE, Danielson AL et al (1997). Mood improvement following daily left prefrontal repetitive transcranial magnetic stimulation in patients with depression: a placebocontrolled crossover trial. Am J Psychiatry 154: 1752-1756. This is the first published RCT of two weeks of daily TMS for depression. The doses were weak by modern standards, and there was no placebo response. Many of the use parameters still being used date from this trial.

George MS, Wassermann EM, Williams WA, Callahan A, Ketter TA, Basser P et al (1995). Daily repetitive transcranial magnetic stimulation (rTMS) improves mood in depression. Neuroreport 6: 1853-1856.

*George MS, Wassermann EM, Williams WA, Steppel J, Pascual-Leone A, Basser $P$ et al (1996). Changes in mood and hormone levels after rapid-rate transcranial magnetic stimulation (rTMS) of the prefrontal cortex. J Neuropsychiatry Clin Neurosci 8: 172-180. This study was required by the IRB and FDA, to show safety and examine whether prefrontal TMS could access limbic regions. The finding of prefrontal specific TMS-induced changes in serum thyroid levels 
showed prefrontal TMS could affect the HPA-axis, and cleared the path for later US clinical trials.

Gomez E, Mikhail AR (1978). Treatment of methadone withdrawal with cerebral electrotherapy. Br J Psychiatry 134: 111-113.

Gradinaru V, Mogri M, Thompson KR, Henderson JM, Deisseroth K (2009). Optical deconstruction of Parkinsonian neural circuitry. Science (NY) 324: 354-359.

Grisaru N, Yarovslavsky U, Abarbanel J, Lamberg T, Belmaker RH (1994). Transcranial magnetic stimulation in depression and schizophrenia. Eur Neuropsychopharmacol 4: 287-288.

Groves DA, Brown VJ (2005). Vagal nerve stimulation: a review of its applications and potential mechanisms that mediate its clinical effects. Neurosci Biobehav Rev 29: 493-500.

Handforth A, DeGiorgio CM, Schachter SC, Uthman BM, Naritoku DK, Tecoma ES et al (1998). Vagus nerve stimulation therapy for partial-onset seizures: a randomized active-control trial. Neurology 51: 48-55.

Hassert DL, Miyashita T, Williams CL (2004). The effects of peripheral vagal nerve stimulation at a memory-modulating intensity on norepinephrine output in the basolateral amygdala. Behav Neurosci 118: 79-88.

Helmstaedter C, Hoppe C, Elger CE (2001). Memory alterations during acute highintensity vagus nerve stimulation. Epilepsy Res 47: 37-42.

Henry TR (2002). Therapeutic mechanisms of vagus nerve stimulation. Neurology 59(Suppl 4): S15-S20.

*Henry TR, Bakay RA, Votaw JR, Pennell PB, Epstein CM, Faber TL et al (1998). Brain blood flow alterations induced by therapeutic vagus nerve stimulation in partial epilepsy: I. Acute effects at high and low levels of stimulation.. Epilepsia 39: 983-990 This was a most important study as it laid the groundwork for the use of VNS in depression, by showing that VNS caused upstream changes in cingulate gyrus, insula and orbitofrontal and prefrontal cortex.

Henry TR, Votaw JR, Pennell PB, Epstein CM, Bakay RAE, Faber TL et al (1999). Acute blood flow changes and efficacy of vagus nerve stimulation in partia epilepsy. Neurology 52: 1166-1173.

Herbsman T, Avery D, Ramsey D, Holtzheimer P, Wadjik C, Hardaway F et al (2009). More lateral and anterior prefrontal coil location is associated with better repetitive transcranial magnetic stimulation antidepressant response. Biol Psychiatry Jun 20. [E-pub ahead of print].

Herwig U, Fallgatter AJ, Hoppner J, Eschweiler GW, Kron M, Hajak G et al (2007). Antidepressant effects of augmentative transcranial magnetic stimulation: randomised multicentre trial. $\mathrm{Br} J$ Psychiatry 191: 441-448.

Herwig U, Padberg F, Unger J, Spitzer M, Schonfeldt-Lecuona C (2001). Transcranial magnetic stimulation in therapy studies: examination of the reliability of 'standard' coil positioning by neuronavigation. Biol Psychiatry 50: 58-61.

Higgins ES, George MS (2007). The Neuroscience of Clinical Psychiatry: The Pathophysiology of Behavior and Mental Illness. Lippincott, Williams \& Wilkins: Baltimore, MD.

Higgins ES, George MS (2008). Brain Stimulation Therapies for Clinicians. American Psychiatric Press: Washington, DC

Hoffman RE, Cavus I (2002). Slow transcranial magnetic stimulation, long-term depotentiation, and brain hyperexcitability disorders. Am J Psychiatry 159: 1093-1102.

Hoflich G, Kasper S, Hufnagel A, Ruhrmann S, Moller HJ (1993). Application of transcranial magnetic stimulation in the treatment of drug-resistant major depression. Hum Psychopharmacol 8: 361-365.

Holmes MD, Chang M, Kapur V (2003). Sleep apnea and excessive daytime somnolence induced by vagal nerve stimulation. Neurology 61: 1126-1129.

Huang Y, Sommer M, Thickbroom GW, Hamada M, Pascual-Leone A, Paulus W et al (2009). Consensus: new methodologies for brain stimulation. Brain Stimulat 2: 2-13.

Hummel FC, Celnik P, Pascual-Leone A, Fregni F, Byblow WD, Buetefisch CM et al (2008). Controversy: noninvasive and invasive cortical stimulation show efficacy in treating stroke patients. Brain Stimulat 1: 370-382.

Huston JM, Gallowitsch-Puerta M, Ochani M, Ochani K, Yuan R, Rosas-Ballina M et al (2007). Transcutaneous vagus nerve stimulation reduces serum high mobility group box 1 levels and improves survival in murine sepsis.[comment]. Crit Care Med 35: 2762-2768.

Hutchinson MR, Coats BD, Lewis SS, Zhang Y, Sprunger DB, Rezvani N et al (2008). Proinflammatory cytokines oppose opioid-induced acute and chronic analgesia. Brain Behav Immun July 1. [E-pub ahead of print].

Joo JH, Solano FX, Mulsant BH, Reynolds CF, Lenze EJ (2005). Predictors of adequacy of depression management in the primary care setting. Psychiatr Serv 56: $1524-1528$

Kew JJ, Ridding MC, Rothwell JC, Passingham RE, Leigh PN, Sooriakumaran S et al (1994). Reorganization of cortical blood flow and transcranial magnetic stimulation maps in human subjects after upper limb amputation. J Neurophysiol 72: 2517-2524

Kolbinger HM, Hoflich G, Hufnagel A, Moller H-J, Kasper S (1995). Transcranial Magnetic Stimulation (TMS) in the treatment of major depression - a pilot study. Hum Psychopharmacol 10: 305-310.
Kolin A, Brill NQ, Broberg PJ (1959). Stimulation of irritable tissues by means of an alternating magnetic field. Proc Soc Exp Biol Med 102: 251-253.

Koo B, Ham SD, Sood S, Tarver B (2001). Human vagus nerve electrophysiology: a guide to vagus nerve stimulation parameters. J Clin Neurophysiol 18: 429-433.

*Krahl SE, Clark KB, Smith DC, Browning RA (1998). Locus coeruleus lesions suppress the seizure-attenuating effects of vagus nerve stimulation. Epilepsia 39: 709-714. . This paper showed how damaging LC activity blocked VNS effects.

Krahl SE, Senanayake SS, Handforth A (2001). Destruction of peripheral C-fibers does not alter subsequent vagus nerve stimulation-induced seizure suppression. Epilepsia 42: 586-589.

Kraus T, Hosl K, Kiess O, Schanze A, Kornhuber J, Forster C (2007). BOLD fMR deactivation of limbic and temporal brain structures and mood enhancing effect by transcutaneous vagus nerve stimulation. J Neural Transm 114: 1485-1493.

Lam RW, Chan P, Wilkins-Ho M, Yatham LN (2008). Repetitive transcranial magnetic stimulation for treatment-resistant depression: a systematic review and metaanalysis. Can J Psychiatry 53: 621-631.

Langguth B, de Ridder D, Dornhoffer JL, Eichhammer P, Folmer RL, Frank E et al (2008). Controversy: does repetitive transcranial magnetic stimulation/transcranial direct current stimulation show efficacy in treating tinnitus patients? Brain Stimulat 1: 192-205.

Lefaucher JP, Drouot X, Nguyen JP (2001). Interventional neurophysiology for pain control: duration of pain relief following repetitive transcranial magnetic stimulation of the motor cortex. Neurophysiol Clin 31: 247-252.

Lefaucheur JP (2004). Transcranial magnetic stimulation in the management of pain. Supp/ Clin Neurophysiol 57: 737-748.

Lefaucheur JP, Drouot X, Keravel Y, Nguyen JP (2001). Pain relief induced by repetitive transcranial magnetic stimulation of precentral cortex. Neuroreport 12 2963-2965.

Li X, Ricci R, Large CH, Anderson B, Nahas Z, George MS (2009). Lamotrigine and valproic acid have different effects on motorcortical neuronal excitability. J Neural Transm 116: 423-429.

Li X, Teneback CC, Nahas Z, Kozel FA, Large C, Cohn J et al (2004). Interleaved transcranial magnetic stimulation/functional MRI confirms that lamotrigine inhibits cortical excitability in healthy young men. Neuropsychopharmacology 29: 13951407

Lisanby S, Luber B, Schroeder C, Osman M, Finck D, Amassian V et al (1998a). rTMS in primates: intracerebral measurement of rTMS and ECS induced voltage in vivo. Electroencephalogr Clin Neurophysiol 107: 79.

Lisanby SH, Luber B, Schroeder C, Osman M, Finck D, Jalinous R et al (1998b). Intracerebral measurement of rTMS and ECS induced voltage in vivo. Biol Psychiatry 43: 100s.

Little JT, Kimbrell TA, Wassermann EM, Grafman J, Figueras S, Dunn RT et al (2000). Cognitive effects of 1 - and 20-hertz repetitive transcranial magnetic stimulation in depression: preliminary report. Neuropsychiatry Neuropsychol Behav Neurol 13: 119-124.

Lockard JS, Congdon WC, DuCharme LL (1990). Feasibility and safety of vagal stimulation in monkey model. Epilepsia 31(Suppl 2): S20-S26.

Lomarev M, Denslow S, Nahas Z, Chae JH, George MS, Bohning DE (2002a). Vagus nerve stimulation (VNS) synchronized BOLD fMRI suggests that VNS in depressed adults has frequency and/or dose dependent effects at rest and during a simple task. J Psychiatr Res 36: 219-227.

Lomarev M, Denslow S, Nahas Z, Chae JH, George MS, Bohning DE (2002b). Vagus nerve stimulation (VNS) synchronized BOLD fMRI suggests that VNS in depressed adults has frequency/dose dependent effects. J Psychiatr Res 36: 219-227.

Loo C, Sachdev P, Elsayed H, MacDarmont B, Mitchell P, Wilkinson M et al (2001). Effects of a 2- to 4 week course of repetitive transcranial magnetic stimulation on neuropsychological functioning, electroencephalogram, and auditory threshold in depressed patients. Biol Psychiatry 49: 615-623.

*Maclean PD (1990). The Triune Brain in Evolution: Role in Paleocerebral Functions. Plenum Press: New York. -672pp. This is one of the most interesting books one of the authors (MSG) has ever read. A real classic of the field.

Malow BA, Edwards J, Marzec M, Sagher O, Ross D, Fromes G (2001). Vagus nerve stimulation reduces daytime sleepiness in epilepsy patients. Neurology 57: 879-884.

Manta S, Dong J, Debonnel G, Blier P (2009). Optimization of vagus nerve stimulation parameters using the firing activity of serotonin neurons in the rat dorsal raphe. Eur Neuropsychopharmacol 19: 250-255.

Marangell LB, Rush AJ, George MS, Sackeim HA, Johnson CR, Husain MM et al (2002). Vagus nerve stimulation (VNS) for major depressive episodes: one year outcomes. Biol Psychiatry 51: 280-287.

Marzec M, Edwards J, Sagher O, Fromes G, Malow BA (2003). Effects of vagus nerve stimulation on sleep-related breathing in epilepsy patients. Epilepsia 44: 930-935. 
Massimini M, Ferrarelli F, Esser SK, Riedner BA, Huber R, Murphy M et al (2007). Triggering sleep slow waves by transcranial magnetic stimulation. Proc Natl Acad Sci USA 104: 8496-8501.

McKay DR, Ridding MC, Thompson PD, Miles TS (2002). Induction of persistent changes in the organisation of the human motor cortex. Exp Brain Res 143: 342349.

Miniussi C, Cappa SF, Cohen LG, Floel A, Fregni F, Nitsche MA et al (2008). Efficacy of repetitive transcranial magnetic stimulation/transcranial direct current stimulation in cognitive neurorehabilitation. Brain Stimulat 1: 326-336.

Mitchell PB, Loo CK (2006). Transcranial magnetic stimulation for depression. Aust N Z J Psychiatry 40: 406-413.

Miyashita T, Williams CL (2003). Enhancement of noradrenergic neurotransmission in the nucleus of the solitary tract modulates memory storage processes. Brain Res 987: 164-175.

Mu Q, Bohning D, Nahas Z, Walker J, Anderson B, Johnson KA et al (2004). Acute vagus nerve stimulation using different pulse widths produces varying brain effects. Biol Psychiatry 55: 816-825.

Nahas Z, Marangell LB, Husain MM, Rush AJ, Sackeim HA, Lisanby SH et al (2005). Two-year outcome of vagus nerve stimulation (VNS) for treatment of major depressive episodes. J Clin Psychiatry 66: 1097-1104.

Nahas Z, Teneback C, Chae JH, Mu Q, Molnar C, Kozel FA et al (2007). Serial vagus nerve stimulation functional MRI in treatment-resistant depression. Neuropsychopharmacology 32: 1649-1660.

Naritoku DK, Terry WJ, Helfert RH (1995). Regional induction of Fos immunoreactivity in the brain by anticonvulsant stimulation of the vagus nerve. Epilepsy Res 22: 53-62.

Neese SL, Sherill LK, Tan AA, Roosevelt RW, Browning RA, Smith DC et al (2007). Vagus nerve stimulation may protect GABAergic neurons following traumatic brain injury in rats: An immunocytochemical study. Brain Res 1128: 157-163.

Nitsche MA, Cohen LG, Wassermann EM, Priori A, Lang N, Antal A et al (2008). Transcranial direct current stimulation: state of the art 2008. Brain Stimulat 1: 206-223.

Nitsche MA, Doemkes S, Karakose T, Antal A, Liebetanz D, Lang N et al (2007). Shaping the effects of transcranial direct current stimulation of the human motor cortex. J Neurophysiol 97: 3109-3117.

O'Reardon JP, Cristancho P, Peshek AD (2006). Vagus nerve stimulation (VNS) and treatment of depression: to the brainstem and beyond. Psychiatry 3: 54-63.

*O'Reardon JP, Solvason HB, Janicak PG, Sampson S, Isenberg KE, Nahas Z et al (2007). Efficacy and safety of transcranial magnetic stimulation in the acute treatment of major depression: a multisite randomized controlled trial. Biol Psychiatry 62: 1208-1216. This manuscript describes the blinded phase of the clinical trial that resulted in FDA approval

Oquendo MA, Baca-Garcia E, Kartachov A, Khait V, Campbell CE, Richards M et al (2003). A computer algorithm for calculating the adequacy of antidepressant treatment in unipolar and bipolar depression. J Clin Psychiatry 64: 825-833.

Ottani A, Giuliani D, Mioni C, Galantucci M, Minutoli L, Bitto A et al (2009). Vagus nerve mediates the protective effects of melanocortins against cerebral and systemic damage after ischemic stroke. J Cereb Blood Flow Metab 29: 512-523.

Palm U, Keeser D, Schiller C, Fintescu Z, Reisinger E, Padberg F et al (2008). Skin lesions after treatment with transcranial direct current stimulation (tDCS). Brain Stimulat 1: 386-387.

Papacostas SS, Myrianthopoulou P, Dietis A, Papathanasiou ES (2007). Induction of central-type sleep apnea by vagus nerve stimulation. Electromyogr Clin Neurophysiol 47: 61-63.

Pape TL, Rosenow J, Lewis G, Ahmed G, Walker M, Guernon A et al (2009). Repetitive transcranial magnetic stimulation-associated neurobehavioral gains during coma recovery. Brain Stimulat 2: 22-35.

Pascual-Leone A, Gates JR, Dhuna A (1991). Induction of speech arrest and counting errors with rapid-rate transcranial magnetic stimulation. Neurology 41: 697-702.

Paulus W (2003). Transcranial direct current stimulation (tDCS). EEG Clin Neurophys 56(Suppl): 255-276.

Paulus W, Classen J, Cohen LG, Large CH, Di Lazzaro V, Nitsche M et al (2008). State of the art: pharmacologic effects on cortical excitability measures tested by transcranial magnetic stimulation. Brain Stimulat 1: 151-163.

Pavlov VA (2008). Cholinergic modulation of inflammation. Int J Clin Exp Med 1: 203-212.

Poreisz C, Boros K, Antal A, Paulus W (2007). Safety aspects of transcranial direct current stimulation concerning healthy subjects and patients. Brain Res Bull 72: 208-214.

Pridmore S, Oberoi G (2000). Transcranial magnetic stimulation applications and potential use in chronic pain: studies in waiting. J Neurol Sci 182: 1-4.

Radman T, Ramos R, Brumberg JC, Bikson M (2008). Role of cortical cell type and neuronal morphology in electric field stimulation. Brain Stimulat 1: 247-248.
Radna RJ, MacLean PD (1981a). Vagal elicitation of respiratory-type and other unit responses in basal limbic structures of squirrel monkeys. Brain Res 213: 45-61.

Radna RJ, MacLean PD (1981b). Vagal elicitation of respiratory-type and other unit responses in striopallidum of squirrel monkeys. Brain Res 213: 29-44.

Rhebergen D, Beekman AT, Graaf R, Nolen WA, Spijker J, Hoogendijk WJ et al (2009). The three-year naturalistic course of major depressive disorder, dysthymic disorder and double depression. J Affect Disord 115: 450-459.

Ridding MC, Rothwell JC (1995). Reorganisation in human motor cortex. Can J Physiol Pharmacol 73: 218-222.

${ }^{*}$ Ridding MC, Rothwell JC (2007). Is there a future for therapeutic use of transcranial magnetic stimulation? Nat Rev Neurosci 8: 559-567. This is a very conservative overview of the area which argues that clinical applications should not proceed until there is better understanding of the biological effects of the methods, and of the diseases in question.

Rollnik JD, Dauper J, Wustefield S, Mansouri S, Karst M, Fink M et al (2003). Repetitive Magnetic Stimulation for the treatment of Chronic Pain Conditions. EEG Clin Neurophys (Suppl).

Roslin M, Kurian M (2001). The use of electrical stimulation of the vagus nerve to treat morbid obesity. Epilepsy Behav 2: S11-S16.

Roth BJ, Momen S, Turner R (1994). Algorithm for the design of magnetic stimulation coils. Med Biol Eng Comput 32: 214-216.

Roth Y, Zangen A, Hallett M (2002). A coil design for transcranial magnetic stimulation of deep brain regions. J Clin Neurophysiol 19: 361-370.

Roth Y, Zangen A, Voller B, Hallett M (2005). Transcranial magnetic stimulation of deep brain regions: evidence for efficacy of the H-coil. Clin Neurophysiol 116: $775-779$

Rothwell JC, Hallett M, Berardelli A, Eisen A, Rossini PM, Paulus W (1999). Magnetic stimulation: motor evoked potentials. The International Federation of Clinical Neurophysiology. EEG Clin Neurophys Supp/ 52: 97-103.

Rush AJ, George MS, Sackeim HA, Marangell LB, Husain MM, Giller C et al (2000). Vagus nerve stimulation (VNS) for treatment-resistant depressions: a multicenter study. Biol Psychiatry 47: 276-286.

Rush AJ, Kraemer HC, Sackeim HA, Fava M, Trivedi MH, Frank E et al (2006a). Report by the ACNP Task Force on response and remission in major depressive disorder. Neuropsychopharmacology 31: 1841-1853.

Rush AJ, Marangell LB, Sackeim HA, George MS, Brannan SK, Davis SM et al (2005a). Vagus nerve stimulation for treatment-resistant depression: a randomized, controlled acute phase trial. Biol Psychiatry 58: 347-354.

Rush AJ, Sackeim HA, Marangell LB, George MS, Brannan SK, Davis SM et al (2005b). Effects of 12 months of vagus nerve stimulation in treatment-resistant depression: a naturalistic study. Biol Psychiatry 58: 355-363.

Rush AJ, Trivedi MH, Wisniewski SR, Stewart JW, Nierenberg AA, Thase ME et al (2006b). Bupropion-SR, sertraline, or venlafaxine-XR after failure of SSRls for depression. N Engl J Med 354: 1231-1242.

Sacco PDTJR, Thickbroom GW (2009). Corticomotor responses to triple-pulse transcranial magnetic stimulation: effects of interstimulus interval and stimulus intensity. Brain Stimulat 2: 36-40.

Sackeim HA, George MS (2008). Brain Stimulation — basic, translational and clinical research in neuromodulation: why a new journal? Brain Stimulat 1: 4-6.

Sackeim HA, Keilp JG, Rush AJ, George MS, Marangell LB, Dormer JS et al (2001a). The effects of vagus nerve stimulation on cognitive performance in patients with treatment-resistant depression. Neuropsychiatry Neuropsychol Behav Neurol 14: 53-62.

Sackeim HA, Keilp JG, Rush AJ, George MS, Marangell LB, Dormer JS et al (2001b). The effects of vagus nerve stimulation on cognitive performance in patients with treatment-resistant depression. Neuropsychiatry Neuropsychol Behav Neurol 14: 53-62.

Sackeim HA, Rush AJ, George MS, Marangell LB, Husain MM, Nahas Z et al (2001c). Vagus nerve stimulation (VNS) for treatment-resistant depression: efficacy, side effects, and predictors of outcome. Neuropsychopharmacology 25: 713-728.

Schlaepfer TE, Frick C, Zobel A, Maier W, Heuser I, Bajbouj M et al (2008). Vagus nerve stimulation for depression: efficacy and safety in a European study. Psychol Med 38: 651-661.

Schlaug G, Renga V (2008a). Transcranial direct current stimulation: a noninvasive tool to facilitate stroke recovery. Expert Rev Med Devices 5: 759-768.

Schlaug G, Renga V, Nair D (2008b). Transcranial direct current stimulation in stroke recovery. Arch Neurol 65: 1571-1576.

Schutter DJLG (2008). Antidepressant efficacy of high-frequency transcranial magnetic stimulation over the left dorsolateral prefrontal cortex in double-blind sham-controlled designs: a meta-analysis. Psychol Med 39: 65-75.

Shahwan A, Bailey C, Maxiner W, Harvey AS (2008). Vagus nerve stimulation for refractory epilepsy in children: more to VNS than seizure frequency reduction. Epilepsia 50: 1220-1228. 
Siebner HR, Bergmann TO, Bestmann S, Massimini M, Johansen-Berg $H$, Mochizuki $\mathrm{H}$ et al (2009). Consensus paper: combining transcranial stimulation with neuroimaging. Brain Stimulat 2: 58-80.

Smith DC, Tan AA, Duke A, Neese SL, Clough RW, Browning RA et al (2006). Recovery of function after vagus nerve stimulation initiated 24 hours after fluid percussion brain injury. J Neurotrauma 23: 1549-1560.

Stagg CJ, Wylezinska M, Matthews PM, Johansen-Berg H, Jezzard P, Rothwell JC et al (2009). The neurochemical effects of theta burst stimulation as assessed by magnetic resonance spectroscopy. I Neurophysiol 101: 2872-2877.

Ten Doesschate MC, Koeter MW, Bockting CL, Schene AH (2009). Health related quality of life in recurrent depression: a comparison with a general population sample. J Affect Disord.

Theodore WH, Hunter K, Chen R, Vega-Bermudez F, Boroojerdi B, Reeves-Tyer P et al (2002). Transcranial magnetic stimulation for the treatment of seizures: a controlled study. Neurology 59: 560-562.

Tononi G, Koch C (2008). The neural correlates of consciousness: an update. Ann NYAcad Sci 1124: 239-261.

Trivedi MH, Rush AJ, Wisniewski SR, Nierenberg AA, Warden D, Ritz L et al (2006). Evaluation of outcomes with citalopram for depression using measurementbased care in STAR ${ }^{\star} D$ : implications for clinical practice. (see comment). Am J Psychiatry 163: 28-40.

Van Bockstaele EJ, Peoples J, Telegan P (1999a). Efferent projections of the nucleus of the solitary tract to peri-locus coeruleus dendrites in rat brain: evidence for a monosynaptic pathway. J Comp Neurology 412 410-428.

Van Bockstaele EJ, Peoples J, Valentino RJ (1999b). Anatomic basis for differential regulation of the rostrolateral per-locus coeruleus region by limbic afferents. Bio Psychiatry 46: 1352-1363.

Van Bockstaele EJ, Pieribone VA, Aston-Jones G (1989). Diverse afferents converge on the nucleus paragigantocellularis in the rat ventrolateral medulla: retrograde and anterograde tracing studies. J Comp Neurology 290: 561-584.

Van Der Zanden EP, Boeckxstaens GE, de Jonge WJ (2009). The vagus nerve as a modulator of intestinal inflammation. Neurogastroenterol Motil 21: 6-17.

Wassermann EM (1997). Report on risk and safety of repetitive transcranial magnetic stimulation (rTMS): suggested guidelines from the International Workshop on Risk and Safety of rTMS (June 1996). Electroencephalogr Clin Neurophysiol 108: 1-16.

Yiend J, Paykel E, Merritt R, Lester K, Doll H, Burns T (2009). Long term outcome of primary care depression. J Affect Disord.

Zabara J (1985a). Peripheral control of hypersynchronous discharge in epilepsy. Electroencephalogr Clin Neurophysiol 61s: S162.

Zabara J (1985b). Time course of seizure control to brief, repetitieve stimuli. Epilepsia 26: 518

Zabara J (1992). Inhibition of experimental seizures in canines by repetitive vagal stimulation. Epilepsia 33: 1005-1012.

Ziemann U, Paulus W, Nitsche MA, Pascual-Leone A, Byblow WD, Berardelli A et al (2008). Consensus: motor cortex plasticity protocols. Brain Stimulat 1: 164-182. 